\title{
Exploring a new model of public administration in a digital age: automation, digitization and transparency Jean Y Djamen, $\mathrm{PhD}$ \\ CEO, Orionis Group, 100 Overlook Center $2^{\text {nd }}$ Floor Princeton NJ 08540 USA djamen@,orionisgroup.com
}

\begin{abstract}
This paper describes a model of digital governance that reproduces within the system essential features of public administration while establishing logic for their utilization. The ultimate goal is to be able to confine all participants to their respective roles and responsibilities in public service delivery.
\end{abstract}

Keywords: Public administration; Political-administrative system; Public policy; Public service; Government bureaucracy; Governance; Artificial intelligence; Automation; Digitization; Transparency.

\section{Introduction}

The ultimate goal of public administration is to ensure that public service is rendered in accordance with the policies enacted by a government committed to its citizens. Sound policies, along their implementation are meant to cope with citizens' needs and improve their life through a variety of services rendered. In this regard, poor public service might originate from poor policies whose effects are spread throughout the government bureaucracy framework upheld by the political-administrative system.

In modern governments, a political-administrative system is made up of three branches: the legislative, executive and judiciary; "each of which is supported by bureaucracy". Bureaucracy refers to "the administrative structure that operates upon the direction of the executive; and functions are distributed across multiple government departments that in turn are subdivided in multiple units" (Vigoda-Gadot and Raadschelders, 2015, chapter 6).

Accordingly, poor public service may derive not only from ill-devised (or nonimplemented) policies, but also from stakeholders' moral failings (Davidson Frame 2012, Chapter 5) or the gap between theory and practice when it comes to effective policymaking, to cite a few key factors.

Kiser and Ostrom (1982) propose a distinction between three levels of analysis (and understanding) of political-administrative systems: a constitutional level related to the foundation of a polity (i.e. the formal legislation); a collective level about decision making (i.e. the stakeholders) and an operational level describing the day-to-day operations (i.e. the implementation). In this regard, Vigoda-Gadot and Raadschelders (2015, Chapter 2) have conducted a study dedicated to analyzing public policy and administration cases as well as 
similarities and differences in modern governments across the globe. While harnessing the three levels of analysis, they "opted for a problem-oriented approach and a framework that allows for comparison across continents, nations, levels of government, policies, and time". As pointed-out in Raadschelders (2003), many research works and studies about public administration are based on Kiser and Ostrom's three levels of analysis.

Although the levels put forth are useful in analyzing political-administrative systems individually or collectively and handle some reasoning prospects about governance, research and studies should rather be directed towards models and mechanisms that reproduce the political-administrative system into the machine so as to help public administration play its role in a modern state. In this regard, understanding and representing human intelligence related to government bureaucracy is a prerequisite.

\section{Literature review}

Public policies can be viewed as a set of deeds propped by laws and regulations that are constantly designed, fine-tuned and enacted for the creation, organization or functioning of the government. A simple representation of government bureaucracy is anchored by an organizational structure (Cf. Mohr 1982) that "defines how activities are directed toward the achievement" of the aim (Pugh 2007). An organizational structure indistinctively displays, at multiple levels of granularity, all entities referenced by the (enacted) deeds. For example, the bureaucracy of the United States can be visualized through an organizational structure with a federal government divided in departments, the departments subdivided in units, the units segmented in subunits... (Raadschelders, 2011) Tasks and processes are rarely or never represented in the organizational structure, but are assumed to be implicitly subsumed in the government decision-making.

In keeping with Max Weber's definition of the state as the only actor that has the authority to use coercion or violence in the administration of the sovereignty, VigodaGadot and Raadschelders (2015, chapter 2) define government as referring to "all organizations that operate within an institutional superstructure in which sovereignty is invested and where its officials have the authority to make binding decisions of all people living in that sovereignty". They also describe governance as referring to "all institutional arrangements in society that are created to address challenges that individual effort and capacity cannot resolve". Indeed, governance is globally the management of the business of government (Miller 2015) or precisely the management of an administration under governance at various levels of granularity (Djamen 2008, p. 30).

In the course of public service delivery and with regard to the organizational structure, the institutional superstructure and its subdivisions are acting in the same way or manner at their specified levels of granularity. They are set to act like well-structured entities of a political-administrative system subsuming individuals in office with specified tasks assigned and resources allotted to ensure their managerial autonomy. A government is 
therefore an administration under governance, as well as a government department, a department unit or any other government subdivision, as long as these organizations are autonomous and bear some interest for some stakeholders. Overall, an administration under governance is the subject under study during the course of service delivery. As a result, the segmentation of government bureaucracy is also the fine-tuning of the related (administration under) governance. For example, the description of the department of health and human services (DHHS) at a certain level of the government bureaucracy of the United States (Cf. Raadschelders, 2011) is also the presentation of the DHHS as the administration under governance at that level of reasoning. At a similar level, the administration under governance would be the DHS (for a public service related to the department of homeland security), etc.; and at a higher level, the administration under governance is the federal government.

The focus should always be on the administration under governance at hand, where, in the midst of government bureaucracy, three entities are necessary (and should be sufficient), to reason about governance matters: the administrative structures, the stakeholders, and the governance missions. As a matter of fact, these three entities are retrievable from any public policies enacted in modern age governments. It's worth noting that if policymaking is the very first process of a bureaucracy in a political-administrative system (Vigoda-Gadot and Raadschelders, 2015) it's also the very first place where to detect enablers of poor public service delivery, although public policy design, implementation and enforcement vary from countries, governments and organizations.

\section{Discussion 1: understanding and representing government bureaucracy Administrative structures}

Administrative structures are the organized entities of an administration under governance, geographically or artificially established in one or more local or remote sites. Public administration consists of a set of sub-governance administrations with (or without) multiple levels of granularity, well represented by an organizational structure made up of administrative structures. For example, the DHHS (of the federal government of the United States referred to above) and its divisions or subdivisions are administrative structures of the administration under governance dubbed DHHS.

\section{Stakeholders}

Vigoda-Gadot and Raadschelders (2015, chapter 6) describe three categories of individuals: political officeholders, civil servant and citizen. This categorization doesn't encompass the full sense of governance in an administration under governance, because public administration consists not only of a set of stakeholders acting in-house (at multiple ranks) but also from outside (for multiple purposes). More precisely, a stakeholder is any entity which plays a role, has interest in or derives wellbeing from the management of the 
business of the administration under governance. In Figure 1 presenting the network of stakeholders in public service, internal stakeholders are clearly distinguished from the external ones; the governing authority and the staff being the sole internal (or in-house) stakeholders while all other actors are considered external. This distinction is consistent with the above definitions of government and governance. As a result, seven categories of stakeholders are needed in a well-structured organization (Djamen 2008, p. 42) ${ }^{1}$ and their potential behaviors can be forecast as shown in Table 1.

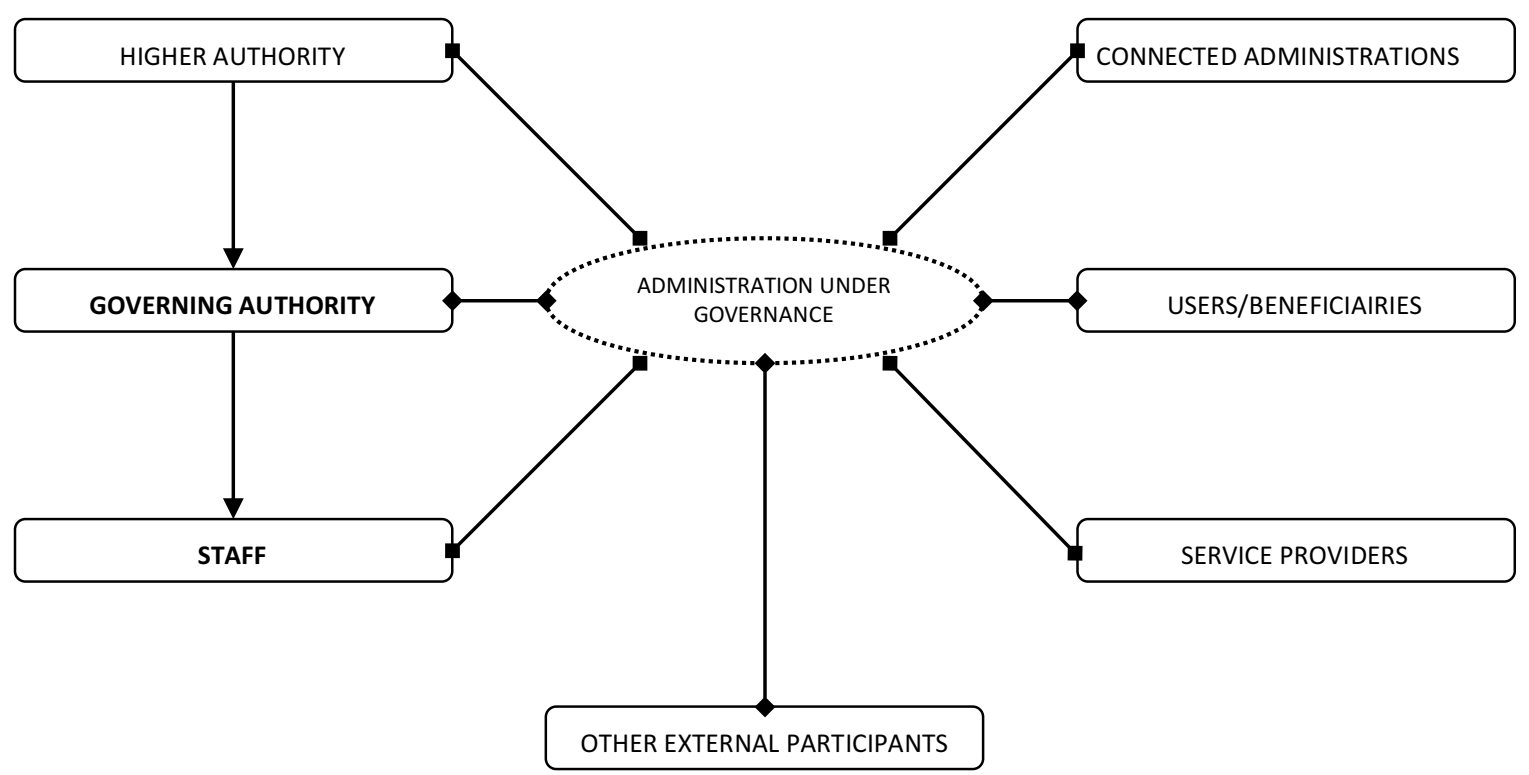

Figure 1: An administration under governance and its seven categories of stakeholders

\footnotetext{
${ }^{1}$ See also https://www.linkedin.com/pulse/seven-categories-stakeholders-well-structured-jean-yvesdjamen?published=t
} 
Table 1: potential behaviors of governance stakeholders

\begin{tabular}{|c|c|c|}
\hline $\begin{array}{l}\text { GOVERNANCE } \\
\text { STAKEHOLDERS }\end{array}$ & $\begin{array}{l}\text { NORMAL OR ADMISSIBLE } \\
\text { BEHAVIORS }\end{array}$ & $\begin{array}{c}\text { DEVIANT OR INADMISSIBLE } \\
\text { BEHAVIORS }\end{array}$ \\
\hline Higher Authority & $\begin{array}{l}\text { Strategic and political development; } \\
\text { monitoring, control, supervision... }\end{array}$ & $\begin{array}{l}\text { No strategy (policy, supervision, monitoring, } \\
\text { or control), interference in missions assigned } \\
\text { to the governing authority... }\end{array}$ \\
\hline Governing Authority & $\begin{array}{l}\text { Missions performed in compliance } \\
\text { with regulation in force, supervision of } \\
\text { intermal personnel... }\end{array}$ & $\begin{array}{l}\text { No supervision (control...), interference in } \\
\text { missions assigned to internal personnel... }\end{array}$ \\
\hline Internal Personnel & $\begin{array}{l}\text { Missions performed in compliance } \\
\text { with the regulation in force and good } \\
\text { practices... }\end{array}$ & $\begin{array}{l}\text { No compliance with good practices, partisan } \\
\text { or selective handling of files, request physical } \\
\text { presence of recipients of services... }\end{array}$ \\
\hline Users & $\begin{array}{l}\text { File tracking, Information retrieval, } \\
\text { claims... }\end{array}$ & $\begin{array}{l}\text { Impatience, distuption of internal personnel's } \\
\text { work, carelessness in file tracking or } \\
\text { indiscipline during the retrieval of } \\
\text { information... }\end{array}$ \\
\hline $\begin{array}{l}\text { Connected } \\
\text { Administrations }\end{array}$ & $\begin{array}{l}\text { Notification of deeds issued to entities } \\
\text { concemed, preferably using modem } \\
\text { information and communication } \\
\text { techniques (internet, rapid mail...) }\end{array}$ & $\begin{array}{l}\text { Documents issued or used are unreliable, } \\
\text { unavailable or inaccessible... }\end{array}$ \\
\hline Services providers & $\begin{array}{l}\text { Supply of goods and services in } \\
\text { compliance with the regulation in force } \\
\text { and good practices... }\end{array}$ & $\begin{array}{l}\begin{array}{l}\text { Fictitious contracts; } \\
\text { performed contracts... }\end{array} \\
\text { non- or wrongly }\end{array}$ \\
\hline $\begin{array}{l}\text { Other external } \\
\text { Stakeholders (public, } \\
\text { people, NGOs, } \\
\text { donors...) }\end{array}$ & $\begin{array}{l}\text { Independent and extemal appraisal, } \\
\text { draft solutions... }\end{array}$ & $\begin{array}{l}\text { Interference in the management of business, } \\
\text { requirement of implementation of a policy or a } \\
\text { specific strategy... }\end{array}$ \\
\hline
\end{tabular}

\section{Governance missions}

Public administration also consists of governance missions assigned either to the administration under governance or specifically to some internal stakeholders, notwithstanding the type of organizational structure (e.g. Lim et al 2010). Governance missions refer to a set of administrative tasks or actions which, when successfully performed, lead to meeting the expected governance targets. The missions are generally recorded in documents which define the nature of the tasks to be performed, as well as the established processes to carry them out. They are made up of global missions assigned to the governing authority, and specific missions assigned to the staff.

\section{Organic chart of governance}

Three types of organizational structures emerge from the definition of an administration under governance. The first is made up of administrative nodes representing the administration under governance and its subdivisions. The second is a set of stakeholders' nodes anchoring the governing authority and the staff. The third represents missions' nodes with the overall governance missions and specific/specialized governance 
missions. The links between administrative nodes are consistent with the segmentation of the government. The links between stakeholders' nodes are consistent with both the rank of individuals in the bureaucracy and their proximity to the governing authority. Figure 2 presents an organizational structure of a government department with a mix of administrative and stakeholders' nodes. Missions' nodes are linked with regard to government functions as inscribed in enacted policies. However, governance missions' overlapping is not necessary in line with the break-down of department subdivision, stakeholders' ranking or the proximity of staff with the governing authority.

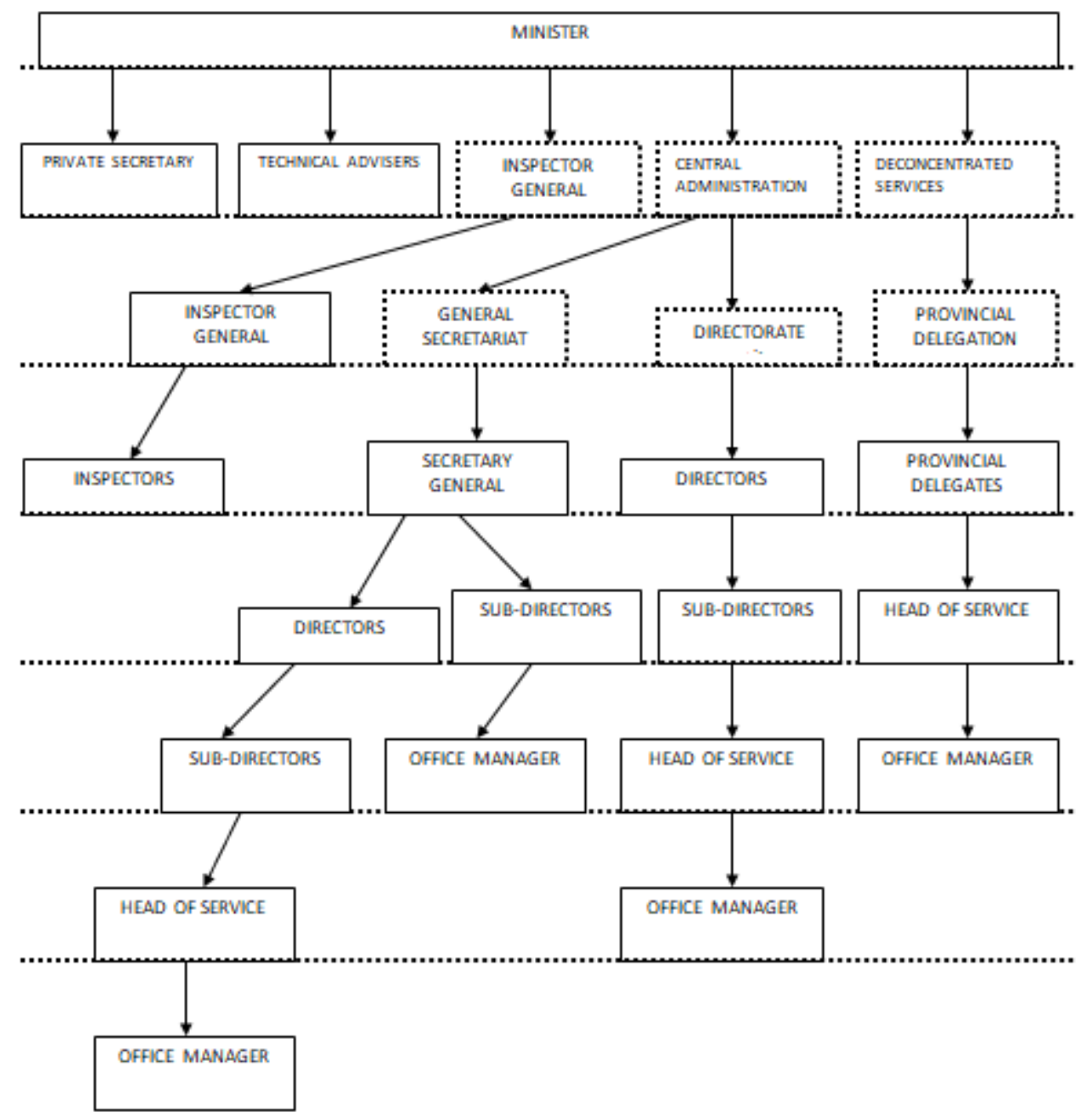

Figure 2: An example of organizational structure (Djamen 2008)

These three types of structures are merged in an organic chart of governance where each node is a tryptic \{structure, actor, mission\} simultaneously representing an administrative structure, the corresponding internal stakeholder(s) and the assigned missions. When harnessed, the new structure produces useful information about 
governance, including (but not limited to) the consistency and suitability of policies enacted by the political-administrative system. An organic chart of governance is shown in Figure 3 where $A D M s$ represent administrative structures and $A G s$, internal stakeholders (missions features are not displayed). Provided the policies enacted regarding an administration under governance are available in a machine-readable format, a computer program could convert all provisions into the organic chart, by automatically detecting the necessary entities and representing them at their appropriate levels in the structure.

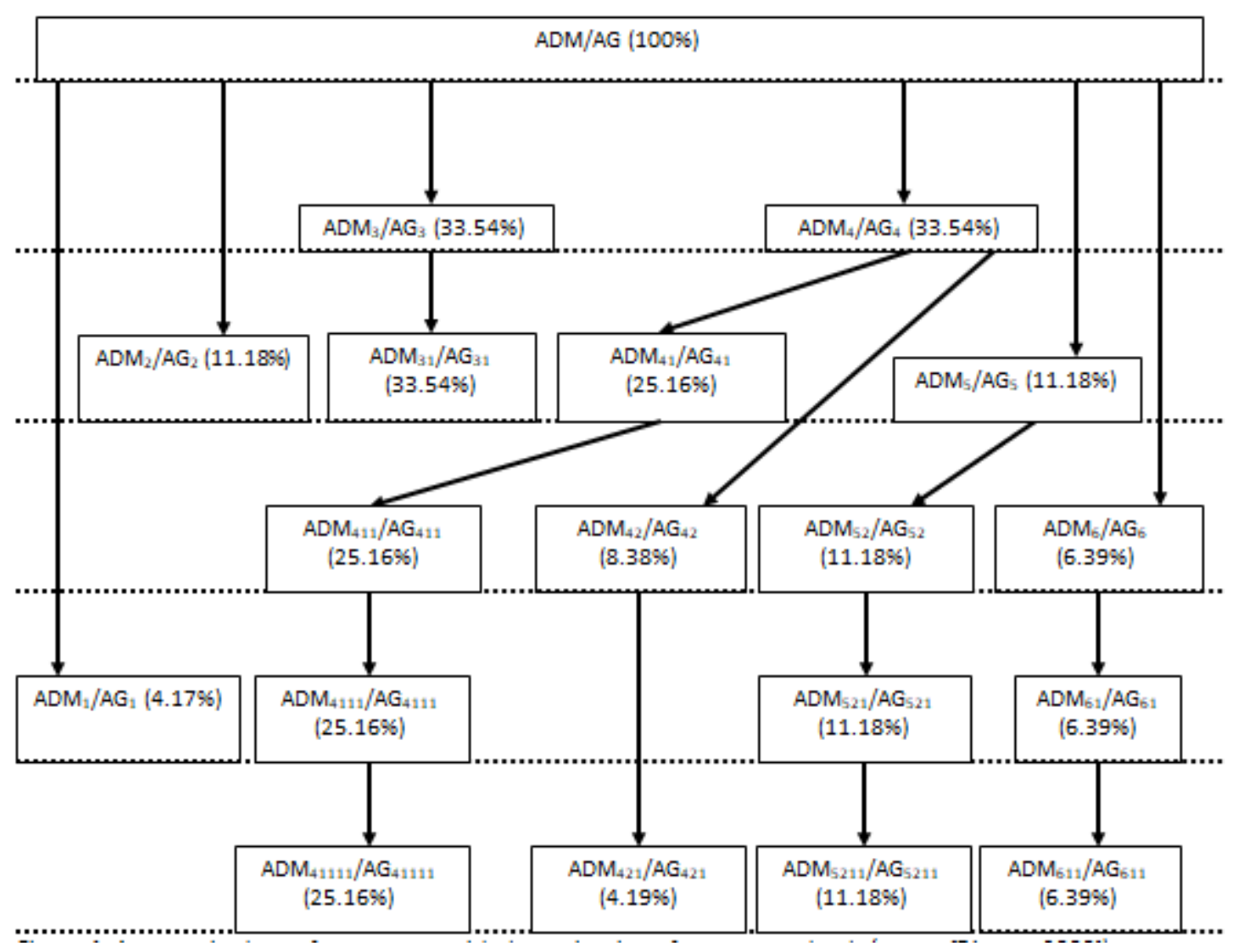

Figure 3: An organic chart of governance with determination of governance loads (Djamen 2008, p. 128)

Eschewing poor public service in government bureaucracy requires the detection of enablers (preferably before their appearance in the timeline of service delivery), as well as their timely fixation. For example, Table 2 presents a case of outdated policies in Customs administration of Cameroon. Policies enacted in 2003 for the then Directorate of Customs show all entities well described. In 2005, new policies enacted repealed the former structure and created the current Directorate General of Customs with additional assignments. However, three important entities were missing: the internal structures, the associated personnel and their specialized missions. As a result, some old provisions were still in force 
on the field in 2005 albeit the repealing of the 2003 act. In 2008 a correction was made but the internal personnel of the Directorate General of Customs were still those appointed in the 2003 act (already repealed).

Table 2: An example of public policy conflict situation as shown in 2011

\begin{tabular}{|l|c|c|c|c|l|c|}
\cline { 2 - 7 } \multicolumn{2}{c|}{} & \multicolumn{2}{c|}{ Institution } & \multicolumn{2}{c|}{ Stakeholders } & \multicolumn{2}{c|}{ Missions } \\
\hline $\begin{array}{l}\text { Policies } \\
\text { enacted } \\
\text { in }\end{array}$ & $\begin{array}{l}\text { Principal } \\
\text { entity }\end{array}$ & $\begin{array}{l}\text { Internal } \\
\text { structures }\end{array}$ & $\begin{array}{l}\text { Governing } \\
\text { authority }\end{array}$ & $\begin{array}{l}\text { Internal } \\
\text { staff }\end{array}$ & $\begin{array}{l}\text { Global } \\
\text { missions }\end{array}$ & $\begin{array}{l}\text { Specialized } \\
\text { missions }\end{array}$ \\
\hline 2003 & $\checkmark$ & $\checkmark$ & $\checkmark$ & $\checkmark$ & $\checkmark$ & $\checkmark$ \\
\hline 2005 & $\checkmark$ & & $\checkmark$ & & $\checkmark$ & \\
\hline 2008 & $\checkmark$ & $\checkmark$ & $\checkmark$ & & $\checkmark$ & $\checkmark$ \\
\hline
\end{tabular}

An organic chart of governance is a mechanism that can virtually be generalized at any level of granularity of the political-administrative system to unveil plentiful flaws in policies enacted. The underpinning algorithm can be applied to constitutions as well. For instance, Figure 4 shows a part of the organizational structure generated for the current constitution of Cameroon ${ }^{2}$ where the so-called three powers are scattered. As per the provisions, the political power is made up of the legislative, executive, judiciary branch, and other powers.

${ }^{2}$ https://www.constituteproject.org/constitution/Cameroon_2008?lang=en 


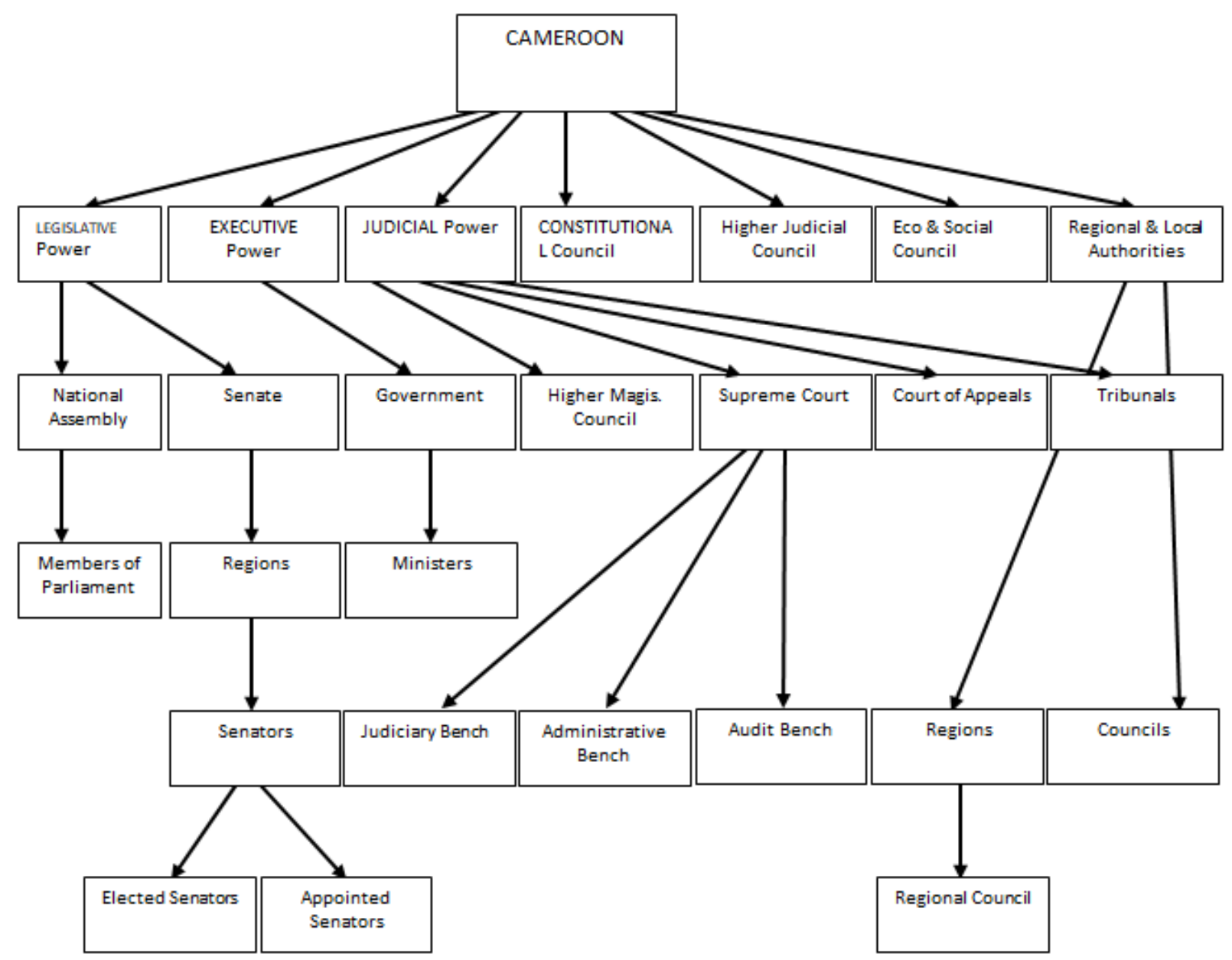

Figure 4: An organizational structure derived from the constitution of Cameroon

\section{Governance loads}

The organic chart can be used to determine governance loads entrusted to the administration under governance. Three types of loads are imbedded in the structure: the weight of administrative structures, the responsibility of stakeholders and the value of missions. The determination of loads enables the detection of potential deviances encompassed in enacted policies, such as missing or conflicting assignments, unbalanced institutions, missions overload. The responsibility ( $\operatorname{Imp}$ ) of internal stakeholders is given by the following formula:

$$
\begin{aligned}
& \operatorname{Imp}\left(A G, p_{1}\right)=1 \\
& \operatorname{Imp}\left(A G_{i j} p_{n}\right)=\left(\operatorname{Imp}\left(A G_{i}\right)-\sum \operatorname{Imp}\left(f d A G_{j}, p_{m}\right)\right) / N b\left(f d A G_{j}, p_{o}\right) /\left(p_{n}-p_{p}\right)
\end{aligned}
$$

The total and full management of the business is incumbent on the governing authority. Hence the responsibility of the said authority is $100 \%$ (or 1 ). The second line of the formula in three panels perfectly reflects the reality of staff members' accountability. 
The first part allows the subtraction of the responsibility of lower ranking management officers, once the responsibility of the line executive is established. The second part allows the redistribution on a pro rata basis of the remaining responsibility to the remaining stakeholders. As for the last part, it contributes, during the redistribution process, to take into account the rank of each stakeholder, the higher ranking officers' responsibility being heavier than that of the lower ranking ones. The same reasoning applies to the weight ( $\mathrm{Wgt})$ of administrative structures:

$\operatorname{Wgt}\left(A D M, p_{1}\right)=1$

$W g t\left(A D M_{i j}, p_{n}\right)=\left(W g t\left(A D M_{i}\right)-\sum W g t\left(f d A D M_{i j} p_{m}\right)\right) / N b\left(f d A D M_{j}, p_{o}\right) /\left(p_{n}-p_{p}\right)$

This formula contributes to the fair distribution of the load of the parent node (authority) to its child nodes (collaborators) in ideal conditions (e.g. child nodes are at the same depth and the distance between the parent and the child is exactly 1). The (most) potentially disruptive factor of this uniform allotment is the re-attachment of nodes of the same depth (officers of the same rank) to different parent nodes (different authorities), be those parent nodes (or not) of the same depth. In spite of such an influence, in an organic chart reflecting well drafted policies (laws), there should not be a significant gap between the loads of nodes of the same depth. A disproportionate gap would be a valuable indicator to be taken into consideration in the assessment of the quality of the government bureaucracy. Hence the notion of threshold to set a reference point. Accordingly, the hypertrophy and atrophy threshold prescribe respectively the maximum values and minimum values of a node in an organic chart. A node is said hypertrophied when its load is superior to the threshold of hypertrophy. Inversely, a node is said atrophied when its load is inferior to the atrophy threshold. The purpose of such an approach is to enhance the detection of certain deviations or conceptual shortcomings which could have crept into the laws and regulations. The hypertrophy or atrophy impact of a node should reflect on the governance responsibility of the stakeholder considered, as well as on the values of missions assigned.

In fact, governance missions can be viewed as a set of roles and responsibilities entrusted to internal stakeholders, or a set of loads carried-out by an administration under governance. The overall missions assigned to the governing authority are furthermore split up or specialized to map the organizational structure. The full value of missions assigned to an internal stakeholder is determined by the load of the corresponding node in the organic chart. It is intuitively a matter of allocating the load of the node proportionally to the number of missions related to that node. Thus, simple equations could be used for automatic determination of the value $(\mathrm{Val})$ of an enacted mission such as:

\begin{tabular}{|c|c|c|}
\hline $\operatorname{Val}\left(M_{0}\right)$ & $=$ & $W g t(A D M /$ mumber of missions assigned to $A G$ \\
\hline $\operatorname{Val}\left(M_{\text {in }}\right)$ & $=$ & $W g t(A D M) /$ mumber of missions assigned to $A G_{i}$ \\
\hline $\operatorname{Val}\left(M_{50}\right)$ & $=$ & $W g t\left(A D M_{j}\right) /$ mumber of missions assigned to $A G_{j y}$. \\
\hline
\end{tabular}


Pursuant to this approach, the load of a node does not only determine the weight of the corresponding administrative structure and the answerability of the managing internal stakeholder, but also the value of missions assigned to the said node. Hence, the following equation with $n$ varying from 1 to the number of missions assigned to $A G$ : $\operatorname{Wgt}(A D M)=$ $\sum \operatorname{Val}\left(M_{n}\right)$. A value may be manually or discretionally granted to a mission depending on its importance to the enabled stakeholder, provided it is done in keeping with the constraints of physical equations requiring that the total amount of the values of the missions be (at most) equal to the total load of the related node.

Within the graph of missions, a child node may encapsulate broken-down missions depending on several composite missions encapsulated in different parent nodes. Tacit values are hidden in missions laid down by the organizational structure and may be disclosed in two phases. Firstly, by spreading down a signal from the root to terminal nodes using the load automatically allotted to various terminal nodes. Secondly, by spreading up a signal from terminal nodes back to the root. This backward propagation contributes to the determination of the reliability of the splitting up of missions assigned to a node. More precisely, the real value of a mission is determined by the sum of values generated by its specialization (its splitting up). This conversion process allows not only the understanding and graphic representation of public policies, but also the detection of potential deviances encompassed in enacted policies, such as missing or conflicting assignments, unbalanced institutions, missions overload, outdated policies, etc. The graph structure might also be used to assert the validity of public administration theories. Take for example the comparative constitution project (CCP - http://comparativeconstitutionsproject.org; https://www.constituteproject.org) that gathers all (current and passed) constitutions. A computer program could parse all CCP's current constitutions in other to produce for each state or nation, useful information (for governance assessment, cross comparison...) including the organizational structures explained above, the governance loads...

Understanding government bureaucracy as discussed above paves the way to reproducing government bureaucracy into the machine.

\section{Discussion 2: reproducing government bureaucracy in the machine}

Government bureaucracy is set to be replicated in the machine through multiple prospects, three of which are of a paramount interest for the efficiency of public service delivery, namely automation, digitization and transparency.

\section{Automation}

Numerous deviations await an organization with un-automated or inadequately defined rules. It is important not only to clearly define (and specify) the missions assigned to a governing authority, but also to make sure that manual processing will not prevail where automation should take shape. In this respect, automation prospects seek to promote 
the automation of all tasks or actions necessary to achieve governance missions assigned to internal stakeholders. Government bureaucracy can be viewed as a set of tasks, clearly identified, computerized and complying with the policies enacted. In modern government, internal stakeholders achieve governance missions by performing their duty and generating governance data with the assistance of the machine.

The aim of automation prospects is to achieve a mechanism embedding all government bureaucracy automatisms enabling the internal stakeholders to comply strictly with the management rules in force. The automation architecture subsumes the (1) automation of existing manual procedures, (2) embedment of automated procedures and (3) automatic processing of governance missions. Some deviations of automation are likely to occur in case of inadequate computerization (unqualified service providers...) or a misuse of automated system (unskilled internal stakeholders...), with a significant potential impact on the quality of public service (Cf. Djamen 2015, p. 76). Automation of government bureaucracy can range from total (i.e. all missions have corresponding automated functions effectively used by internal stakeholders) to non-existent. It is therefore important to be knowledgeable on the automation degree of a political-administrative system.

\section{Digitization}

The potential disruptions of data handled in automation prospects are likely to divert government bureaucracy from enacted governance objectives. Concerns arising include those related to the authenticity, integrity and security of information entered into automated systems and data generated by these systems in consideration of laws in force. In this regard, government bureaucracy is a collection of data clustered according to a static view corresponding to entry instructions into automation prospects' systems, and a dynamic view using data resulting from the processing of such systems. In this regard, an administration under governance and its connected administrations are virtually connected in a network, called (good) governance virtual network, through functional (consumption or production) links (Djamen 2008, p. 163).

The aim of static digitization prospects is to automate all administrative deeds provided or generated by external stakeholders and used by internal stakeholders for the achievement of their missions. The use of these deeds leads to the setting up of one or more databases referred to as initial data or static data. The main risks in wait for static digitization prospects bear on the reliability of mechanisms to ascertain documents. The degree of static digitization relies on both the establishment of static databases (digitization and extraction) and elements to be checked (authentication). Thus, its determination bears both on the number of functional production linkages and the nature of those links.

The purpose of dynamic digitization prospects is to secure and preserve integrity of data handled in the automation prospects by converting to digital technology the data drawn from the performance of internal stakeholders' missions. Such data, referred to as dynamic, 
generally enable to retrace the trend of alterations in government data handled by internal stakeholders. Some automation and static digitization deviations may impact negatively on dynamic digitization prospects, as data generated by an administration under governance heavily depend on several factors, including data input, processing manner (manual or automated), quality and pertinence of automatic processing, and particularly, the matching of automatic processing with human information system to which the said processing refers. The degree of dynamic digitization is based upon the building of dynamic databases (digitization and dynamic extraction) and its use (notification, filing, etc.).

\section{Transparency}

There are certain transparency constraints to be fulfilled by any politicaladministrative system in the modern age. Firstly, legal texts enacted apply to all participants. Secondly, beneficiaries of public services are entitled to rightful responses upon their requests. Therefore, government bureaucracy is made up of a whole set of information that should be made available to stakeholders. Such information is of two kinds. The first (static transparency) bears on laws and regulations governing the performance of governance missions. The second (dynamic transparency) bears on the various successive phases inherent in the progress of the achievement of governance missions.

The purpose of static transparency prospects is to make available to stakeholders all the legal instruments governing an administration under governance. Official gazettes gathering legal instruments enforceable in many countries are actually available online through electronically format (pdf, word, html...). The CCP project in partnership with Google Ideas is an example of static transparency system, where data about constitutions around the world are collected in order to be read, searched and compared. Thus, the degree of static transparency of government bureaucracy bears on various laws and regulations integrated in the implementation of automation prospects. Its determination depends, not only on volume measurement inherent in various legal instruments in force, but equally on the accessibility to such instruments.

The purpose of dynamic transparency is to make available to some stakeholders a set of information keeping them on the track of their files being handled by internal stakeholders. For example, bulletin boards are used in most organizations to stick a set of public information, including the progress report on various files being handled by internal stakeholders. Sometimes electronic bulletin boards are posted up online through the internet. The degree of dynamic transparency of a government bureaucracy should contribute to assess how determined to inform the recipients of service a politicaladministrative system is. 


\section{Governance prospects}

Considered separately, automation, digitization and transparency prospects lead to the development of basic governance reasoning for the implementation of three types of automated systems to respectively secure government processing, government data and the dissemination of information. In integration (see Figure 5), these prospects widen the reasoning scope and facilitate the determination of governance level in a politicaladministrative system.

The quality of public service delivery depends on a loop where all external data must go through static digitization prospects (1), before any consideration in automation prospects which should be consistent with policies enacted (2). Public policies are static as they cannot be altered during the course of the service (4). Moreover, data processed in automation prospects must go through dynamic digitization prospects (3) and dynamic transparency prospects (5). 


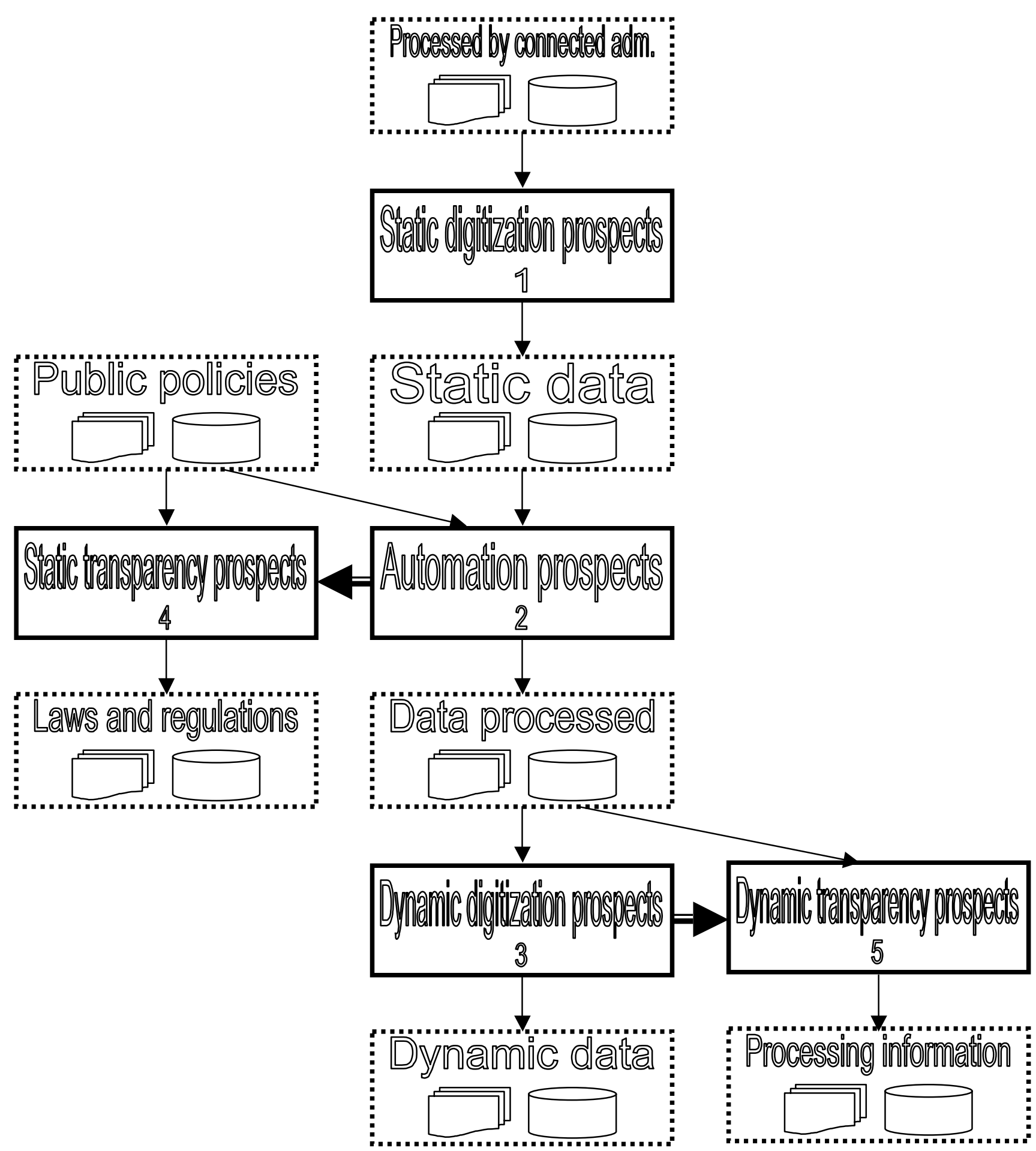

Figure 5: Architecture of governance prospects in the digital age 


\section{Conclusion}

At this stage in the development of public administration, the main challenge is to restrict participants to their respective roles and responsibilities during the course of public service delivery.

The suggested model harnesses public policies by automatically generating an electronic structure to better assess policy suitability. Furthermore, this electronic structure aids in the performance of other important reasoning tasks for the enhancement of public service delivery.

As effective public service increases in value, the future of public administration unavoidably trends towards amplification in the use of technology.

\section{References}

Davidson Frame J. (2012). Framing decisions: decision-making that accounts for irrationality, people and constraints. John Wiley \& Sons, 304 pages.

Djamen J-Y. (2008). Gouvernance et Intelligence Artificielle - Bâtir une Administration Performante. Yaoundé, Cameroun: Afredit.

Djamen J-Y. (2011). Professionalism and the promotion of the implementation of the public service charter in the public sector in Africa: Role of human resource management, facilitation factors, inhibition factors and strategic actions. Capacity Building Workshop on "Promoting Professionalism in the Public Service: Strengthening the Role of Human Resource Managers in the Public Sector for the effective implementation of the Charter for Public Service in Africa. Addis Ababa, Ethiopia: United Nations. http://unpan1.un.org/intradoc/groups/public/documents/undpadm/unpan044912.pdf

Djamen J-Y. (2015). The role of Information and Communication Technology in Improving the Evaluation of Performance in the Public Service in Africa. In Scott G K \& Wallis M (Eds), Performance Management for Improving Public Service in Africa (pp. 6585). AAPAM, Nairobi, Kenya: Ramko Printing Works Ltd.

Miller K. J. (2015). "Chapter 1, The Future of the Discipline: Trends in Public Sector Management" In Emerging and Potential Trends in Public Management: An Age of Austerity. Published online: 09 Mar 2015; 1-24. http://dx.doi.org/10.1108/S20457944(2012)0000001004

Kiser, L. L., Ostrom, E. (1982). The Three Worlds of Action: A Metatheoretical Synthesis of Institutional Approaches. In E. Ostrom (Ed.), Strategies of Political Inquiry (pp. 179-222). Beverly Hills: Sage.

Lim, M., Griffiths ZG., Sambrook S. (2010). Organizational structure for the twenty-first century. Annual meeting of The Institute for Operations Research and the Management Science, Austin. 
Mohr L. B. (1982). Explaining organizational behavior: the limits and possibilities of theory and research. Jossey-Bass Publishers.

Pugh D. S. (2007). Organization theory: Selected readings. Fifth edition, 704 pages, UK: Penguin.

Raadschelders, J. C. N. (2011) The Study of Public Administration in the United States. Public Administration (UK), 89(1), 140-155.

Vigoda-Gadot E., Raadschelders J. (2015). Global dimensions of public administration and governance: a comparative voyage. Hoboken New Jersey: Jossey-Bass, a Wiley brand. 